\section{ARENDT, EICHMANN Y LA BANALIDAD DEL MAL*}

\author{
Marina López \\ Universidad de San Nicolás de Hidalgo \\ Michoacá - México
}

\begin{abstract}
In this text I describe the characteristics that Hannah Arendt attributes to the SS agents through the figure of Eichmann, during the German Nazi regime of the 20th century. According to this characterization, I intend to show, on the one hand, that there is not a break in Arendt's thought on evil, i.e. from The Origins of Totalitarianism to Eichmann in Jerusalem: a report on the banality of evil, but a continuous line of thought. And, on the other hand, I try to follow the clues that Arendt gives concerning the "banality" that defines the behavior of individuals such as Eichmann. Both premises will permit me to point out what, in my understanding, the banalization of humanity implies, not only in the context of the Jewish Holocaust, but in each of the societies in which the elimination of spontaneity is a reality.
\end{abstract}

KEY WORDS: Totalitarianism; Banality of evil; Holocaust; Eichmann.

La noción de "banalidad del mal" apareció en la obra de Hannah Arendt, aunque sin detalles conceptuales, en 1963 cuando se publicó su elaboración del reporte del juicio de Otto Adolf Eichmann, uno de los criminales de guerra especialmente famoso, realizado en Jerusalén el año de 1961. El reportaje, Eichmann en Jersusalén, un estudio sobre la banalidad del mal, alcanzó especial significación tanto por la formulación que adquiría la existencia del mal como por la distinción entre no pensar y estupidez que, según Hannah Arendt, caracterizó la actitud del acusado: "ausencia de pensamiento no quiere decir estupidez; puede encontrarse en personas muy inteligentes, y no proviene de un mal corazón; probablemente sea a la inversa, que la maldad puede ser causada por la ausencia de pensamiento" (Arendt, 1984, 24). Es esta ausencia de pensamiento lo que motivó a Hannah Arendt a investigar acerca de la vida de la mente ${ }^{1} y$, con ello, el origen del mal aunque ya no en el libro sobre el reportaje, sino en La vida del espíritu.

La controversia ${ }^{2}$ que suscitó la afirmación de la banalidad del mal de Eichmann en Jerusalén... no sólo se debe a la gravedad de su formulación, sino también a que se presenta como una aparente ruptura en las consideraciones

\section{ARENDT, EICHMANN AND THE BANALITY OF EVIL}

RESUMEN: En el texto se describen las características que Hannah Arendt, a través de la figura de Eichmann, atribuye a los agentes SS durante el régimen nazi alemán de mediados del siglo XX. Con la caracterización se persigue mostrar, en principio, que no hay una ruptura en el pensamiento de Hannah Arendt respecto a su manera de considerar el mal, desde Los origenes del Totalitarismo hasta Eichmann en Jerusalén, un estudio sobre la banalidad del mal, sino una continuidad $y$, por otra parte, seguir las pistas que Arendt propone en torno a la "banalidad" que define el comportamiento de individuos como Eichmann. Ambas premisas nos permitirán poner de relieve lo que, a nuestro parecer, implica la banalización de la humanidad no sólo en el contexto del Holocausto judio, sino en cada una de las sociedades en las que la eliminación de la espontaneidad es una realidad.

PALABRAS CLAVE: Totalitarismo; Banalidad del mal; Holocausto; Eichmann.

de Hannah Arendt. En Los orígenes del Totalitarismo el mal tenía el carácter de radical, mientras que en Eichmann en Jerusalén es banal. Esta ruptura es casi más bien una contradicción aunque sea dicha diez años después de la publicación de Los orígenes del totalitarismo. Hannah Arendt, no obstante, reduce sus consideraciones a un nivel donde la importancia del tema se diluye, a pesar de que afirme en carta a Sholem que "ha cambiado de opinión" respecto al tema. Pero que sólo es una aparente ruptura lo confirman las palabras de Arendt en la misma carta: "opino que el mal no es nunca 'radical', que sólo es extremo, y que carece de toda profundidad y de cualquier dimensión demoníaca" (Arendt, 2004, 150).

La obra de Hannah Arendt desde Los orígenes del Totalitarismo contiene, a mi ver, una defensa de la dignidad humana: el principio sobre el que se sostiene no sólo el mundo sino toda comunidad política; y es desde la noción de "banalidad del mal" que se aproxima al carácter completamente novedoso y absoluto del régimen nazi, del Totalitarismo y de sus posibilidades permanentes. $Y$ todavía más: una de las características del sistema Totalitario es que no sólo actuó sobre sus víctimas, sino además, y 
ésa fue la garantía de su funcionamiento, al eliminar la capacidad de espontaneidad entre ellas en tanto que no protestaron mientras avanzaban hacia su propia muerte, también lo hizo sobre los victimarios entre quienes la obediencia fue un factor común.

En Los orígenes del Totalitarismo, el arma letal y símbolo de las capacidades del régimen Totalitario son, para Hannah Arendt, los campos de exterminio, una realidad que no fue propiamente invento del régimen $y$, sin embargo, funcionaron como la verdadera institución totalitaria. Es en los campos de exterminio donde es posible la eliminación de la identidad de los individuos y la eliminación de las capacidades no sólo de pensamiento sino también sensitivas a través de dos formas de exterminio que confluyen en la desaparición de la persona jurídico-moral y física: "los campos son concebidos no sólo para exterminar a las personas y degradar a los seres humanos, sino también para servir a los fantásticos experimentos de eliminar, bajo condiciones científicamente controladas, a la misma espontaneidad como expresión del comportamiento humano y de transformar a la personalidad humana en una simple cosa, algo que ni siquiera son los animales" (Arendt, 1987, 533). Al punto de que Eichmann, al igual que muchos otros oficiales SS, "superó la necesidad de sentir, en general" (Arendt, 2000, 205) a medida que pasaba el tiempo y él obedecia las leyes dictadas por el Führer. La aniquilación de la espontaneidad y la consiguiente "ausencia de pensamiento" tienen una consecuencia mucho más peligrosa para la vida que el hecho del asesinato porque, afirma Hannah Arendt, sistemáticamente el Totalitarismo extirpó la libertad de los individuos.

Eliminar la espontaneidad y transformar la personalidad son, en este sentido, las formas más infames de exterminio, al punto de que antes de la eliminación física de los internados en los campos era preciso, primero, "matar en el hombre a la persona jurídica" $y$, segundo, "el asesinato de la persona moral en el hombre".

Este proceso de desintegración se desarrolla, según Hannah Arendt en tres estadios: 1. el arresto arbitrario, con el que "se destruye a la persona jurídica no a causa de la injusticia sino a causa de que el arresto no tiene la más mínima relación, cualquiera que sea, con las acciones $u$ opiniones de la persona", 2. la desintegración de la personalidad moral, que "se consigue mediante la separación de los campos de concentración del resto del mundo [situación por la que no atraviesan las cárceles que nunca están fuera de la sociedad, sino que forman parte de su propia estabilidad], una separación que hace del martirio algo sin sentido, vacío, ridículo" y 3 . la destrucción de la individualidad, que "se logra mediante la permanencia e institucionalización de la tortura". El resultado es la reducción de los seres humanos a su "ínfimo denominador común posible de 'reacciones idénticas'" (Arendt, 2005, 296).

$\mathrm{Si}$, por una parte, no hay un pais que reclame el cadáver de las personas desaparecidas $y_{1}$ por otra, esos mismos paises más bien colaboran en la deportación de sus judíos, la muerte física es sólo una consecuencia lógica innecesaria para la permanencia del régimen. De ahí que "el Totalitarismo busca no la dominación despótica sobre los hombres, sino un sistema en el que los hombres sean superfluos" (Arendt, 1987, 554, cursivas de M.L.). 0 en otras palabras, banales, incapaces, por un lado, de desobedecer $y$, por otro, de distinguir el bien del mal y, no obstante, seguir con vida.

Esa capacidad del régimen Totalitario de hacer superfluos a los seres humanos llevó a Hannah Arendt a encontrar, durante el juicio de Eichmann en Jerusalén, que el problema es que el mal no tiene raíces ni "diabólica profundidad". Y más allá de que haya aparecido como condición de la vida humana con el comienzo del tiempo y el nacimiento de los hombres en el mundo, según la distinción que ella misma hace a partir del pensamiento político de san Agustín, tampoco cabe que se acepte en calidad de parte esencial de la condición humana. Que el mal no tenga raíces implica, en términos de las posibilidades del conocimiento, que carece de esencia, la cualidad de todas las cosas a partir de la que es posible acercarse a su naturaleza, como el bien.

Uno de los presupuestos del juicio de Jerusalén era que el mal había sido encarnado en la persona de Eichmann. Éste, sin embargo, no era ningún monstruo y los motivos que lo pudieron haber llevado a cometer los crimenes de los que era acusado no derivaron más que de su "naturaleza idealista" (el éxito para Eichmann era la única razón por la que cabía dar credibilidad y sentir respeto por alguien más), pese a lo que Eichmann "habría sido incapaz de matar a un superior para heredar su cargo" ${ }^{3}$. 
El problema está en otra parte y el comportamiento de Eichmann lo sacó a relucir en el proceso del juicio: a Eichmann, en más de una ocasión, le traicionó la memoria, era incapaz de recordar cualquier cosa excepto las frases hechas del lenguaje burocrático que se empleaba en el régimen, al punto de atribuirse actos que las pruebas documentales mostraban que no habian sido de su autoria, como el proyecto Madagascar (que consistía en transportar a los judíos y colocarlos en una patria) y aceptar haber sido el autor de la muerte de millones de judíos, cuando sus funciones se limitaron a las negociaciones en torno al transporte útil a la deportación de judios a los distintos campos.

En este sentido, no sólo resulta molesto calificar a Eichmann como un sujeto del montón, banal o vulgar dependiendo del uso de los términos, en la medida en que no cabe la menor duda de que tuvo el papel de "deportador" de judios en el régimen nacionalsocialista; molesto también es que en función de sus acciones se pretenda (al menos así se quiere interpretar) justificar las más monstruosas actividades realizadas por un grupo de hombres sobre todo un pueblo. Sin embargo, y aunque la adjetivación está utilizada en función de la persona de Eichmann, su comportamiento es una de las características más generales de los individuos durante el Totalitarismo: "lo más grave en el caso de Eichmann es que hubo muchos hombres como él, y que estos hombres no fueron pervertidos ni sádicos, sino que fueron, y siguen siendo, terrible y terroríficamente normales" (Arendt, 2000, 417).

¿Pero cuáles son, pues, esas características generales de los hombres como Eichmann a las que Hannah Arendt se refiere? ¿En qué radica la banalidad del mal en los agentes SS? "Cuando hablo de banalidad del mal [indica Hannah Arendt en el 'Post Scriptum' de Eichmann en Jerusalén] lo hago solamente a un nivel estrictamente objetivo, y me limito a señalar un fenómeno que, en el curso del juicio, resultó evidente" (Arendt, 2000, 433): que "Eichmann no era estúpido", simplemente no pensaba. No habia en él esa capacidad de reflexión a través de la que es posible distinguir lo que está bien de lo que está mal. En este sentido, "una de las lecciones que nos dio el proceso de Jerusalén fue que tal alejamiento de la realidad y tal irreflexión pueden causar más daño que todos los malos instintos inherentes, quizá, a la naturaleza humana" (Arendt, 2000, 434s).
Y estas son las peculiaridades que Hannah Arendt encontró en Eichmann.

1) Se declaró "inocente en los términos en que se formula la acusación", y aseguró que nunca había matado a ninguna persona judía o no, ni ordenado que le dieran muerte a persona alguna, porque, según dijo, "no tuve que hacerlo"; pero, por otra parte, también afirmó que "hubiera matado a su propio padre, si se lo hubieran ordenado" (Arendt, 2000, 41).

2) Eichmann no enfrentaba cargos de conciencia porque había hecho todo cuanto se le había pedido, de lo contrario "hubiera llevado un peso en ella en el caso de que no hubiera cumplido las órdenes recibidas, las órdenes de enviar a la muerte a millones de hombres, mujeres y niños, con la mayor diligencia y meticulosidad" (Arendt, 2000, 46).

3) Eichmann no constituía un caso de insanía moral. Declaró que "nunca tuvo nada contra los judíos", y en caso de ser un sádico no se le habría condenado a la muerte sino que se le habría encerrado en un manicomio. El problema de los jueces para no creerle, fue que eran "demasiado honestos, o quizá estaban convencidos de los conceptos que forman la base de su ministerio, para admitir que una persona 'normal', que no era ni un débil mental ni un cínico, ni un doctrinario, fuera totalmente incapaz de distinguir el bien del mal" (Arendt, 2000, 47).

4) $Y$, por otra parte, Eichmann siempre presentó dificultades para recordar lo que hacia y el momento preciso en que sucedía tal o cual cosa.

a) Eichmann recordaba poco, tanto en sus declaraciones como en la biografía que escribió mientras estuvo en prisión, la manera en que cambió de uno a otro trabajo en el transcurso de su vida anterior a su ingreso en el partido en 1932. Falseó constantemente respecto a que si su padre le había conseguido un empleo o él mismo lo había solicitado diciendo que le habian ofrecido importantes puestos en esta o aquella compañía.

b) Eichmann, por otra parte, tenía una gran propensión a "atribuirse méritos ajenos": "pretender

ARBOR CLXXXVI 742 marzo-abril [2010] 287-292 ISSN: 0210-1963 
atribuirse la muerte de cinco millones de judios, aproximadamente el total de pérdidas sufridas a causa de los esfuerzos combinados de todas las oficinas y autoridades nazis era absurdo, y él lo sabía perfectamente" (Arendt, 2000, 77). La tarea de Eichmann estaba encaminada a deportar judios, porque en todo aquel complejo burocrático "sabía organizar y negociar". Por lo que si bien es cierto que sus actividades abarcaron la totalidad de Europa no fue porque él fuera alguien influyente sino porque en su calidad de deportador de judíos debía tratar los asuntos pertinentes al caso en todo el continente.

c) Eichmann era incapaz de considerar cualquier cosa "desde el punto de vista de su interlocutor". Su único lenguaje era el burocrático que, a pesar de su deficiente memoria, Eichmann repetía constantemente: "sólo necesitaba recordar su pasado para sentirse seguro de que no mentía y de que no se estaba engañando a sí mismo, ya que él y el mundo en que vivió habian estado, en otro tiempo, en perfecta armonía" (Arendt, 2000, 83). El autoengaño, en este punto, fue fundamental no sólo para los oficiales SS sino para la población común alemana, porque se había convertido en un requisito moral para sobrevivir. Y también para las víctimas. Este es otro de los aspectos del libro constantemente reprochados a Hannah Arendt, por cuanto que coloca en el centro de sus investigaciones sobre el Totalitarismo la participación judía, que no fue sino otro resultado del régimen ${ }^{4}$.

d) Y, por último, la existencia de una "mendacidad sistemática" permitía a Eichmann recordar las frases hechas y el lenguaje en clave utilizado durante el régimen, aunque no recordara "con exactitud la fecha del estallido de la guerra o la invasión a Rusia". Este fue el factor decisivo para que Eichmann no experimentara cargo de conciencia alguno, pues tenía la frase hecha que le provocaba la mayor "satisfacción" en cualquier circunstancia. Esta costumbre no lo abandonaría, precisa Hannah Arendt, ni en el último momento, al punto de olvidar que "se trataba de su propia muerte" al declarar: "Dentro de muy poco, caballeros, volveremos a encontrarnos. Tal es el destino de todos los hombres. ¡Viva Alemania! ¡Viva la Argentina! ¡Viva Austria! Nunca las olvidaré" (Arendt, 2000, 382).

Pero la gravedad de estas circunstancias no se encuentra en que se considere, finalmente, a Eichmann o bien como alguien del montón, o como alguien que se comportaba según la norma al interior del régimen, sino que al hacerlo se evaden consecuencias sumamente peligrosas para la humanidad entera y no sólo para un individuo, "porque tratamos de comprender el comportamiento psicológico de los internados en los campos de concentración y de los hombres de las SS, cuando lo que debe comprenderse es que el verdadero espíritu puede ser destruido sin llegar a la destrucción física del hombre; y que, desde luego, el espíritu, el carácter de individualidad, bajo determinadas circunstancias, sólo parecen expresarse por la rapidez 0 lentitud con la que se desintegran" (Arendt, 1987, 536). La destrucción del espíritu y de la individualidad se logra sin el exterminio propiamente físico, no es necesario y en todo caso resulta inútil, porque quienes permanecen aislados de lo que verdaderamente sucede en realidad no existen.

El exterminio del espíritu es, desde Los orígenes del Totalitarismo, la preocupación de Hannah Arendt en relación a los desarrollos del régimen nacionalsocialista y es, a mi parecer, el punto que para la autora elimina la dignidad humana, de ahí que el problema del mal no sea de carácter moral, jurídico o epistemológico, sino político. No es moral porque no cabe la discusión acerca de si está bien o está mal matar a nuestros semejantes. En ese caso, la condena y ejecución de Eichmann sólo tiene justificación por el hecho de que contribuyó al asesinato de miles de personas y no en que hubiera sido un monstruo o un individuo poseído por el diablo. El problema tampoco es epistemológico: Eichmann no era estúpido, la precisión con que llevaba a cabo su trabajo es una muestra de que conocía a la perfección el departamento en que se desempeñaba. En otras palabras, Eichmann no era estúpido por cuanto que evidenciaba con sus acciones que conocía lo que hacía; pero, no pensaba. $Y$, finalmente, la eliminación de la espontaneidad y la personalidad jurídica y moral de los seres humanos es un crimen contra la dignidad humana, que no requiere forzosamente, deciamos, el exterminio físico, por lo que el problema de la "banalidad del mal" se ubica en el centro de las discusiones de carácter político. 
Fue este proceso de desmantelamiento de la personalidad, de la espontaneidad (según los términos de la propia Hannah Arendt), lo que orilló tanto a víctimas como a victimarios a no protestar sobre lo que les estaba sucediendo. El resultado de ese proceso es la "ausencia de pensamiento" que Hannah Arendt observó en Eichmann en sus declaraciones durante el juicio en que fue procesado en Jerusalén.

En este sentido es que Hannah Arendt resalta que lo terrible no es que los crímenes hayan sido cometidos "contra los judios" sino "contra la humanidad", lo que significa que puede aparecer en cualquier momento en nuestras sociedades en la medida en que, por una parte, hay "un explosivo incremento de la población mundial", avances tecnológicos y desarrollo de la tecnología nuclear que, "a través de la automación, darán a la población el carácter de 'superfluos', incluso desde el punto de vista laboral" se dará lugar a instrumentos que "en comparación con las instalaciones de gastamiento de Hitler parecen un juguete para niños con malas inclinaciones".

Lo que descubrió Hannah Arendt, entre otros asuntos, es que los "crimenes contra la humanidad" o "crímenes contra la condición humana", más allá de la persona de Eichmann, aunque no separados de su comportamiento, no atentan únicamente contra la personalidad e integridad física de las víctimas, sino que también, a la vez que dan lugar a un "nuevo tipo de criminal" (Arendt, 1987, 404), un criminal que comete sus delitos en "circunstancias que casi le impiden saber o intuir que realiza actos de maldad", y que, para que ese nuevo tipo de criminal exista, es necesaria la aniquilación del espíritu; por lo que, en el caso de los crimenes cometidos durante el nacionalsocialismo, sólo las víctimas, y no el delito, "podía ser la consecuencia de la larga historia de antisemitismo y odio hacía los judios" ((Arendt, 1987, 406).

A mi ver, más que colocar a Eichmann en el lugar de un posible arquetipo de la "banalidad del mal", Hannah Arendt continua, en los límites del reportaje, explorando en torno a los peligros que encierran los regímenes burocráticos para el espíritu humano. Una exploración que le permitió observar y señalar no sólo que los cargos por los que Eichmann fue juzgado, condenado y ejecutado no estuvieron exentos de equívocos (respecto a los "crimenes de guerra" y los "crimenes contra el pueblo judio") sino enfatizar en la poca luz que dio el juicio sobre el único crimen que era completamente nuevo, en nada útil a la guerra que se estaba librando y al que cabe esperar en tiempos de paz (Arendt, 2000, 389): los "crimenes contra la humanidad" que son el resultado del proceso de transformación de los seres humanos en funcionarios, como en el caso de los oficiales SS, de todo régimen burocrático.

Poner el énfasis en la destrucción de la espontaneidad, que es posible sin la aniquilación física, nos permite encontrar en Hannah Arendt una historia de los modos en que se ve afectado al espíritu, más que con las actividades propias del pensamiento, con los cambios que la práctica ha proporcionado al mundo. En otras palabras, es en el trabajo de hacer del mundo una casa, donde la humanidad ha creado, más allá de sus objetivos primarios, tanto el modo de comprensión de ese mundo como las maneras de relación más peligrosas para su estabilidad y permanencia.

\section{NOTAS}

* Para Agustín Serrano de Haro, con afecto.

1 The life of the mind, en inglés. La traducción para "mind" no es únicamente "espíritu", el término alude a lo que tiene que ver con la capacidad de la razón, con la mente en general. En inglés no existe "la razón" y, más bien, "reason" alude a las razones 0 motivos que alguien tiene para hacer tal o cual cosa o las causas de que algo sea como sea. "Mind", en cambio, denota la capacidad de la mente, o del espíritu, como se traduce generalmente esta obra de Hannah Aren$\mathrm{dt}$. La mente, en este sentido no tiene que ver únicamente con la capacidad de raciocinio o de pensamiento como se podría deducir de que es también posible traducir el término como razón, sino a un conjunto de capacidades que tienen que ver, según Hannah Arendt, con el pensamiento, la voluntad y el juicio, facultades que no
Recibido: 28 de agosto de 2007

Aceptado: 30 de marzo de 2008 
son visibles ni requieren del mundo sensible para existir.

2 Un asunto que Hannah Arendt interpretó como una campaña política en su contra en la medida en que era vista como quien, con gran resentimiento, no odia sólo a su propio pueblo, sino "a sí misma". Cfr. Young-Bruhel, 1983 y Arendt/McCarthy, 1998.

3 Respecto a este asunto, Sultana Wahnón considera en su reseña del libro de Arendt que de este carácter "idealista" de Eichmann es necesario decir que era "incapaz de distinguir el bien del mal"; razón por la que Hannah Arendt decidió "hablar de la banalidad del mal. Lo que no quiere decir, de ningún modo, que el mal cometido por Eichmann fuera banal, sino que fueron banales los motivos que lo llevaron a cometerlo". A mi ver, Eichmann era banal y nada más, no los motivos que lo llevaron a cometer crimenes que estaban resguardados por su incapacidad de distinguir el bien del mal. Cfr. Wahnón, 2002.

4 Hubo dos factores que contribuyeron al buen funcionamiento del régimen, los consejos y la policía judía y la asignación de categorías entre la población judía. La presencia de estos aspectos funcionó en dos sentidos: 1) la participación de los consejos y la policía judía fue medio para eximir de la pena y la culpa a los nazis; es decir, tenían en los dirigentes judíos otro medio para eliminar los cargos de conciencia por cuanto ellos mismos entregaban o negociaban un número de judíos para su deportación y 2) el uso de categorías funcionó como medio de organización y selección; en otros términos, posibilitaron que la discriminación social apareciera como un hecho aceptable y adecuado, e impidieron dar cuenta real del estado de las cosas en el exterior de un espacio en términos de categorías, y provocaron y alentaron la colaboración de las víctimas.

\section{BIBLIOGRAFÍA}

Arendt, H. (1984): La vida del espíritu, Madrid, C.E.C.

Arendt, H. (1987): Los orígenes del totalitarismo, 3 volúmenes, Madrid, Alianza.

Arendt, H. (2000): Eichmann en Jerusalén, un estudio sobre la banalidad del mal, Barcelona, Lumen.

Arendt, H. (2004): Una revisión de la historia judía y otros ensayos, Barcelona, Paidós.

Arendt, H. (2005): Ensayos de comprensión (1930-1954), Madrid, Caparrós.

Arendt, H./McCarthy, M. (1998), Entre amigas. Correspondencia entre Hannah Arendt y Mary MacCarthy, Barcelona, Lumen.

Wahnón, S. (2002): "Arendt frente a Eichmann", en R. Mate (ed.): La filosofía después del Holocausto, Barcelona, Riopiedras, 360-364.

Young-Bruhel, E. (1983): Hannah Arendt, Valencia, Editions Alfons El Magnanim. 